\title{
RADIATION EMERGENCY PREPAREDNESS: PERCEPTION OF NON-PHYSICIAN FIRST RECEIVERS
}

Singapore Med J 2014; 55(7): 392 doi: 10.11622/smedj.2014094

Dear Sir,

There is a lack of local research on hospital-based radiation emergency preparedness for scenarios such as a dirty bomb detonation. ${ }^{(1,2)}$ We read with interest an article published by $\mathrm{Chin}^{(1)}$ in 2007 on the acute management of radiation poisoning and injuries. The article discussed the importance of appropriate emergency department (ED) triage, acute management of radiation injury and safety of health workers.

We wish to highlight the crucial roles undertaken by non-physician first receivers at the ED (Table I) and share concisely the interesting investigative findings from a recent survey conducted among non-physician participants of a training programme on radiation emergency held at our hospital's ED. A total of 38 health workers - 23 nurses, 11 radiographers, 4 housekeeping staff - responded to the survey. Out of these 38 responders, 14 (37\%) felt 'neutral' or unprepared to handle radioactive hazards in their current roles. Nurses, in particular, felt less prepared than radiographers and housekeepers ( $p=0.002$; Fisher's exact test [2-sided]; Table II). In addition, only $26(68 \%)$ of all the responders indicated that they are 'very likely' or 'likely' to turn up for work in such an event.

Table I. Roles and responsibilities of non-physician ED staff during a radiation emergency.

\begin{tabular}{ll}
\hline Vocation & Examples of roles and responsibilities \\
\hline Nurse & - Clinical care of persistently contaminated victims \\
& - Initial phase of casualty decontamination, or 'hasty decon' \\
Radiographer & - Staffing and preparing the RIR in the ED \\
& - Radiation response teams - casualty screening following decontamination \\
Housekeeper & - Sanaging the surge in demand for radio-imaging \\
& - Setting up the RIR \\
& - Decondling and disposing of radioactive contaminated waste
\end{tabular}

ED: emergency department; RIR: radiation isolation room

Table II. Staff perception of the level of preparedness to handle radioactive hazards in their current role by vocation.

\begin{tabular}{lccc}
\hline Vocation & \multicolumn{3}{c}{ No. (\%) } \\
\cline { 2 - 4 } & $\begin{array}{c}\text { Very unprepared/ } \\
\text { unprepared/neutral }\end{array}$ & $\begin{array}{c}\text { Prepared/ } \\
\text { very prepared }\end{array}$ & Total \\
\hline Nurse* & $13(56.5)$ & $10(43.5)$ & 23 \\
Radiographer/Housekeeper & $1(6.7)$ & $14(93.3)$ & 15 \\
Total & $14(36.8)$ & $24(63.2)$ & 38 \\
\hline
\end{tabular}

${ }^{*} p=0.0021$ (Fisher's exact test [2-sided])

These findings did not come as a surprise. A similar survey conducted overseas has surfaced key concerns such as a lack of readiness, and even disagreement with some aspects of the current response guidance. ${ }^{(3)}$ Although the actual reasons lie beyond this survey, we postulate that nurses, who are directly involved with clinical care and spend a longer period of time with patients (some of whom may be persistently contaminated), perceive themselves to be at greater risk of harm. Unfamiliarity with their roles and a lack of cross-training for expanded responsibilities during a crisis may have added to stress and uncertainty among nurses.

In conclusion, we wish to underscore the importance of careful manpower planning by administrators so as to ensure that competent and trained healthcare providers are present when needed during such a crisis. Our findings also point to an urgent need for education and training.

Yours sincerely,

Hoon Chin Steven $\underline{\operatorname{Lim}}^{1}$, Jun Guan $\underline{\mathrm{Tan}}^{2}$, Muhammad Azmi $\underline{\mathrm{Hezan}}^{2}$

${ }^{1}$ Accident and Emergency Department, Changi General Hospital, ${ }^{2}$ Yong Loo Lin School of Medicine, National University of Singapore, Singapore. hoon_chin_lim@ cgh.com.sg

\section{References}

1. Chin FK. Scenario of a dirty bomb in an urban environment and acute management of radiation poisoning and injuries. Singapore Med J 2007; $48: 950-7$.

2. Lim HC, Ng KS, Tan HH, Leong KW. Hospital preparedness for radiation emergencies and medical management of multiple combined radiation injury victims. Proceedings of Singapore Healthcare 2011; 20:197-207.

3. Becker SM, Middleton SA. Improving hospital preparedness for radiological terrorism: perspectives from emergency department physicians and nurses. Disaster Med Public Health Prep 2008; 2:174-84. 